Bull. Mater. Sci., Vol. 17, No. 6, November 1994, pp. 811-827. (C) Printed in India.

\title{
Preparation and characterization of diamond films
}

\author{
$S$ CHAUDHURI and A K PAL \\ Department of Materials Science, Indian Association for the Cultivation of Science, \\ Calcutta 700 032, India
}

\begin{abstract}
Diamond films were deposited by magnetron sputtering of vitreous carbon disc and also by plasma CVD technique using $\mathrm{C}_{2} \mathrm{H}_{2}+\mathrm{H}_{2}$ or $\mathrm{CO}_{2}+\mathrm{H}_{2}$ gas mixtures. The films were characterized by measuring the electrical, optical and microstructural properties. FTIR and Raman studies were carried out to study the effect of $s p^{2}$ and $s p^{3}$ bonds present in the films. The films had a high mechanical stress which was determined from the broadening of the optical absorption tail in the films.
\end{abstract}

Keywords. Diamond; chemical vapour deposition; sputtering; optical property; electrical property; microstructural study.

\section{Introduction}

Recently, diamond and diamond like carbon (DLC) films attracted much attention due to their high potential for various technological applications. During the last decade various laboratories throughout the world investigated the properties of diamond and DLC films and a large number of papers related to DLC, diamond or similar hard coating materials were published. In recent years, research efforts are mainly directed towards the preparation of diamond and DLC films for various device applications. Fabrication of high temperature, high power and high frequency semiconducting devices using diamond coating are of current interest to the researchers working in this field. Theoretical studies suggest that diamond devices may surpass $\mathrm{Si}$ or GaAs based devices provided several intricate problems which limit the prospect of diamond in device applications may be solved adequately (Collins 1992). Excellent reviews on the electronic properties of diamond and DLC films have been published (Collins 1989, 1990a).

There are various techniques reported so far, for the deposition of diamond films among which magnetron sputtering, variety of chemical vapour deposition (CVD), microwave plasma technique, plasma torch and ion beam deposition are worth mentioning (Badzian et al 1989; Chattopadhyay et al 1993; Bögli et al 1994). All the techniqués have their individual merits and demerits. It has been observed that a low growth rate $\left(0: 1-1 \mu \mathrm{m} \mathrm{h}^{-1}\right)$ was necessary for the production of good quality diamond films (Badzian et al 1989; Collins 1992). The main problem associated with increasing growth rate of diamond is that increase in the deposition rate is always associated with increase in the non-diamond $s p^{2}$ phase. Optical (FTIR) measurement is generally used to determine the ratio of $s p^{3}$ and $s p^{2}$ bonding in diamond films (Dutta et al 1993). Although the absorption associated with the non-diamond carbon ( $s p^{2}$ bonding) may be reduced to a great extent by using suitable deposition condition, it was always found to be large in films compared to that in natural diamond (Collins 1990a). It has been observed that the growth 
rate of CVD diamond films is increased with increase in the vol\% of hydrocarbon in the gas mixture. But, it was also noticed that if the concentration of hydrocarbon is increased too much the non-diamond carbon in the film increases dramatically. Also, appreciable concentration of hydrogen is always found to be present in the deposited film and this excess $\mathrm{H}_{2}$ generally makes the film highly stressed. Although successful growth of diamond requires the presence of atomic hydrogen, small amount of oxygen was observed to enhance the growth of diamond (Saito et al 1990; Chen et al 1992; Glumac and Goodwin 1992). Possibility of growing diamond films at lower deposition temperature $(<700 \mathrm{~K})$ was also explored by several workers (Liou et al 1989; Ong and Chang 1989; Ihara et al 1991).

Choice of substrate is very important for growing diamond films for device application. Electronic grade diamond film requires the use of diamond substrate and diamond film is generally polycrystalline unless a diamond substrate is used. Single crystal diamond may be grown on cubic boron nitride (Koizumi et al 1990). But, single crystal BN is much expensive than using substrates of natural or high pressure synthetic diamond. Possibility of using other substrate materials was also explored. Growth of diamond on cheaper substrates coated with AIN may be useful due to lattice matching of the materials (Vasudev et al 1993). Polycrystalline diamond films, thus produced on non-diamond substrates, have important applications in microelectronic circuits, machine tool industry, optical coatings, X-ray windows, radiation detector and various other technological applications (Vermeulen and Harris 1977; Holiday et al 1992; Wu et al 1992; Ford 1994; Matthews and Eskildsem 1994). The high refractive index and surface roughness often limits the optical application of diamond film. DeNatale et al (1992) produced an antireflection coating on $\mathrm{Ge}$ substrate using polycrystalline diamond film to overcome the outstanding difficulties. Now, thermodynamic principles suggest that perfectly $s p^{3}$ bonded diamond may be produced at practically zero growth rate. This means whatever small growth rate is used for the production of polycrystalline diamond film, it will have considerable density of defect states, which will reside at the grain boundaries. Recently, much work is being done to understand the grain boundary scattering in polycrystalline diamond film (Liou et al 1989) with a view to make the films contain less defects so that the device quality may be improved to make it comparable or even better than that for $\mathrm{Si}$ and GaAs based devices.

The presence of grain (ordered) and grain boundaries (disordered) regions in polycrystalline film necessarily implies the existence of large amount of stress. Now, deposition of diamond films by plasma CVD technique would also culminate in additional inclusion of defects which may in turn add to the already existing mechanical stress due to the grain boundaries. A high compressive stress has been reported by many workers in diamond film (Wanlu et al 1992; Chattopadhyay et al 1994a). Wanlu et al (1992) indicated a decrease in compressive stress with increasing grain size. There are several research groups working on producing homo-epitaxial layers by CVD (Geis et al 1988; Fujimori et al 1990; Gildenblat et al 1990; Grot et al 1991) so that high temperature diodes and field effect transistors may be fabricated. The quality of the homoepitaxial layers produced at present are generally not adequate for the fabrication of devices and non-planar growth along with secondary nucleation are common (Badzian et al 1989) even on a diamond substrate. As a consequence, devices like microwave amplifiers (Brown 1987) or microcircuits with high packing density (Yoder 1987) has been 
tried with an aim to produce devices workable at high temperature and high frequencies, higher than that achieved in GaAs or Si based devices (Simpson 1988). Diamond devices generally suffer from high series resistance (Gildenblat et al 1990; Grot et al 1991) when operated at room temperature. The optimum temperature of operation with low series resistance is $\sim 770 \mathrm{~K}$. But the conductivity of diamond at this temperature, even if doped, is not as good as $\mathrm{Si}$ at room temperature and is much lower than that for GaAs. Further, mobility of diamond film decreases with increasing temperature so that the frequency response becomes worse than that of GaAs devices at the same temperature.

Doping of diamond films have been considered by various workers (Gildenblat et al 1990; Glesener 1993; Tachibana 1993) for electronic applications. Diamond always has $p$-type conductivity and $n$-type diamond does not exist. Boron doping is very effective to make the film $p$-type. Doping of diamond to make it $n$-type is another intricate problem, which could not be solved although it is very important for the fabrication of devices. Doping with arsenic was tried by several workers to have $n$-type films but it was not successful. No technique has yet been developed to impart $n$-type conductivity to diamond film thus ruling out the possibility of bipolar devices. As such, high power devices with diamond may not be viable unless further developments are made. But devices with p-type doping were successfully produced by different workers. Glesener et al $(1991,1992)$ studied the Schottky diode of diamond and aluminium, for which they deposited boron doped diamond films by $\mathrm{CVD}$ of $\mathrm{CO}_{2}+\mathrm{H}_{2}$. Boric acid in methanol was used as the source of boron through which $\mathrm{CO}_{2}$ was passed before introducing it into the deposition chamber.

For the last several years we are working on the preparation and characterization of diamond and DLC films by different methods, e.g. magnetron sputtering of vitreous carbon and CVD techniques. For CVD techniques we have used different precursors like $\mathrm{CO}_{2}+\mathrm{H}_{2}$ and $\mathrm{C}_{2} \mathrm{H}_{2}+\mathrm{H}_{2}$. In this communication, we report our studies on diamond films produced by different techniques and characterized by measuring the electrical, optical and microstructural properties.

\section{Experimental}

Diamond films were deposited on different substrates (e.g. Mo, glass, mica, Si and quartz) by d.c. magnetron sputtering or CVD with substrate temperature $\left(T_{s}\right)$ within $500-1200 \mathrm{~K}$. High substrate temperature always favoured the nucleation of diamond crystallites.

\subsection{Magnetron sputtering technique}

A vitreous carbon disc (of dia $\sim 5 \mathrm{~cm}$ and thickness $\sim 2 \mathrm{~mm}$ ) was used as the target for producing diamond films by dc magnetron sputtering using a mixture of argon and hydrogen. The details of the apparatus and the technique have been reported elsewhere (Chattopadhyay et al 1993). The sputtering (at $1.5 \mathrm{kV}$ and $20 \mathrm{~mA}$ ) was carried out at different partial gas pressures ranging from $10^{-2}$ to $10^{-3} \mathrm{~Pa}$ with $5-10$ vol\% of hydrogen in $\mathrm{H}_{2}+\mathrm{Ar}$ gas mixture. 


\subsection{CVD technique}

We also deposited diamond films by CVD technique by using either $\mathrm{C}_{2} \mathrm{H}_{2}+\mathrm{H}_{2}$ or $\mathrm{CO}_{2}+\mathrm{H}_{2}$ gas mixtures. The gas mixtures were cracked inside a conventional deposition chamber backed by rotary and diffusion pumps.

2.2a From $\mathrm{CO}_{2}+\mathrm{H}_{2}$ : Diamond films were produced by d.c. plasma deposition of $\mathrm{CO}_{2}(3-5$ vol\%) and hydrogen mixtures (Chattopadhyay et al 1994b). The films produced by this technique were doped with boron by passing a portion of $\mathrm{CO}_{2}$ through boric acid, dissolved in ethanol. Requisite mass-flow meter and needle valve arrangements were incorporated so that the gas' mixture, passing through the solution of boric acid in ethanol could be introduced into the deposition chamber at a controlled rate. A thermocouple was inserted by means of a vacuum feed-through into the chamber to measure the substrate temperature.

$2.2 b$ From $\mathrm{C}_{2} \mathrm{H}_{2}+\mathrm{H}_{2}$ : For the deposition of diamond from $\mathrm{C}_{2} \mathrm{H}_{2}+\mathrm{H}_{2}$ gas mixture, a deposition chamber similar to that used for $\mathrm{CVD}$ of $\mathrm{CO}_{2}+\mathrm{H}_{2}$ was used with only exception that we introduced $\mathrm{C}_{2} \mathrm{H}_{2}+\mathrm{H}_{2}$ in different proportions $\left(\mathrm{C}_{2} \mathrm{H}_{2}\right.$ varying within 1-10 vol\%) instead of carbon dioxide + hydrogen gas mixture. It was observed that the films deposited with $\mathrm{C}_{2} \mathrm{H}_{2}$ in the range 1-5 vol\% produced diamond films with higher band gap $(>3.5 \mathrm{eV})$, while films deposited with $\mathrm{C}_{2} \mathrm{H}_{2}$ above 5 vol\% were diamond like carbon (DLC) with lower band gap (1.5-2.8 eV) (Dutta et al 1993).

\section{Results and discussion}

\subsection{Structural studies}

The structure and surface morphologies of the diamond films were studied by XRD, TEM and SEM respectively. The XRD pattern of a representative diamond film prepared by magnetron sputtering of a vitreous carbon target is shown in figure 1 . Strong reflections from (111), (220) and (311) planes could be observed for films deposited on molybdenum and mica substrates kept at $\sim 900-1200 \mathrm{~K}$ during deposition. The above feature compared well with those observed by Celii et al (1992) and Guo and Yu (1992) for diamond films grown by CVD on silicon and molybdenum substrates. The - lattice constant (a) evaluated from XRD studies was equal to $0.3583 \mathrm{~nm}$ which compared well with that obtained by Sawabe and Inuzuka (1986). The crystal size evaluated from the SEM micrographs was found to lie within the range of $0.3-0.6 \mu \mathrm{m}$ (figure 2). An additional peak at $53.4^{\circ}$ for $\mathrm{Mo}_{2} \mathrm{C}$ could be observed in the XRD pattern for diamond films deposited onto molybdenum substrates (figure 1). Films deposited at lower substrate temperature than $850 \mathrm{~K}$ did not indicate any appreciable peak in the XRD pattern.

Figure 2 shows the SEM and TEM micrographs for some representative films deposited onto mica, glass, molybdenum and freshly cleaved $\mathrm{NaCl}$ substrates. The substrate temperature of the glass substrate could not be increased beyond $650 \mathrm{~K}$ and as such definite diamond crystals could not be observed (figure 2a) in these films. The graphite phase predominated for the films deposited onto glass substrates. Number density of the crystallites increased appreciably (figure $2 b$ ) for films 


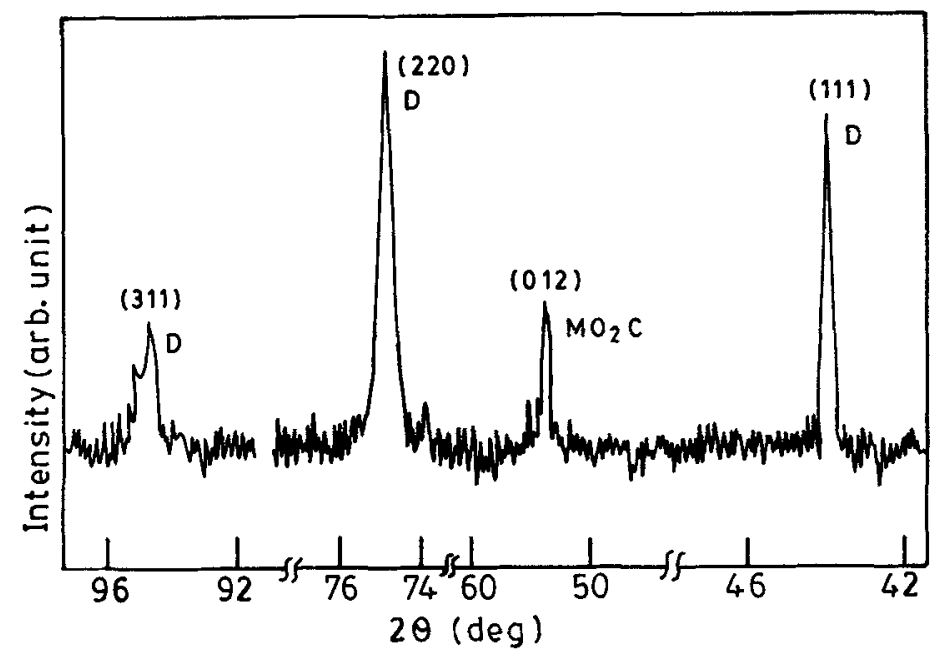

Figure 1. X-ray diffraction pattern of a representative diamond film deposited on Mo by d.c. magnetron sputtering of vitreous carbon target.

deposited onto mica substrates at the same temperature $(\sim 650 \mathrm{~K})$. Films deposited onto molybdenum (figure $2 \mathrm{c}$ ) and mica substrates (figure $2 \mathrm{~d}$ ) at temperatures between $1000-1200 \mathrm{~K}$ clearly revealed the cubic diamond crystals. The TEM micrographs for films deposited on to $\mathrm{NaCl}$ substrates at $\sim 850 \mathrm{~K}$ indicated both polycrystalline (figure $2 e$, zone marked $x$ ) and single crystal zones (figure $2 e$, zone marked $y$ ) to be present in the films. The corresponding diffraction patterns indicated the presence of (111), (022), (113) and (004) planes. The SEM micrograph of the above film deposited onto $\mathrm{NaCl}$ crystal is shown in figure $2 \mathrm{f}$.

The XRD traces of diamond films prepared by d.c. plasma deposition of $\mathrm{CO}_{2}$ and hydrogen gas mixtures were similar to those observed in figure 1 for diamond films deposited from magnetron sputtering of vitreous carbon. Strong reflections were observed corresponding to (111), (220) and (311) planes at $44 \cdot 1^{\circ}, 75^{\circ}$ and $94.5^{\circ}$ respectively. The surface morphology of the diamond films was studied by SEM. Figure 3 shows the scanning electron micrograph of a representative diamond film on mica substrate. Cubic diamond crystallites are visible in the above micrograph in the background (zone $\mathrm{A}$ of figure $3 \mathrm{a}$ ) of polycrystalline diamond, which has been shown separately in figure $3 b$.

Figure 4 shows the SEM micrographs of diamond films deposited on different substrates (mica, quartz and silicon) from cracking of acetylene and hydrogen gas mixture by a d.c. field. It can be seen that the nucleation density is higher for films deposited on silicon substrate. This may perhaps be due to the fact that silicon is a carbide forming material and as such may favour the nucleation of diamond film on it. The XRD pattern for these films was also characterized by the presence of strong peaks of (111), (220) and (311) planes.

\subsection{Raman studies}

The quality of the diamond films was studied by Raman spectroscopy. Raman shift 

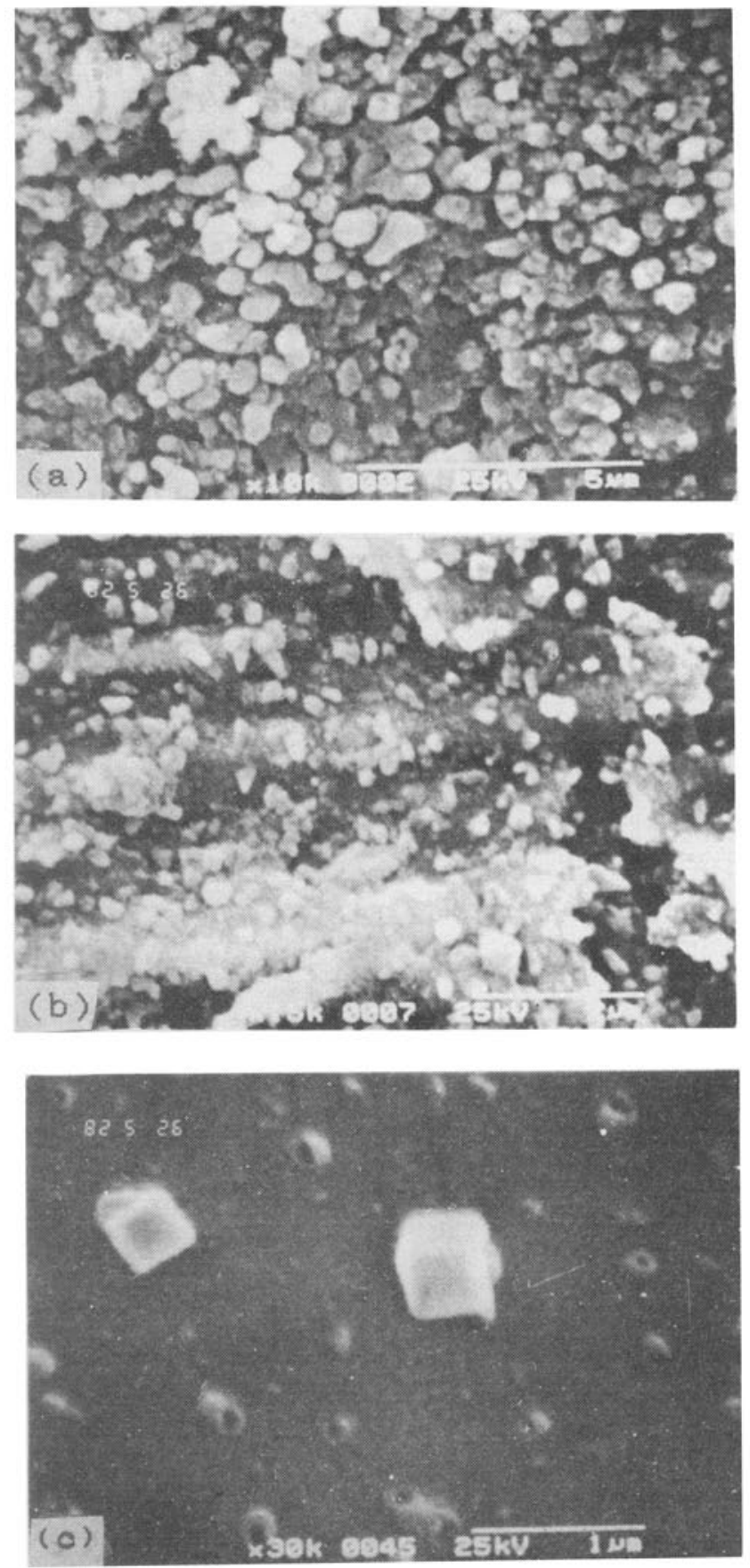

Figure 2a-c. 

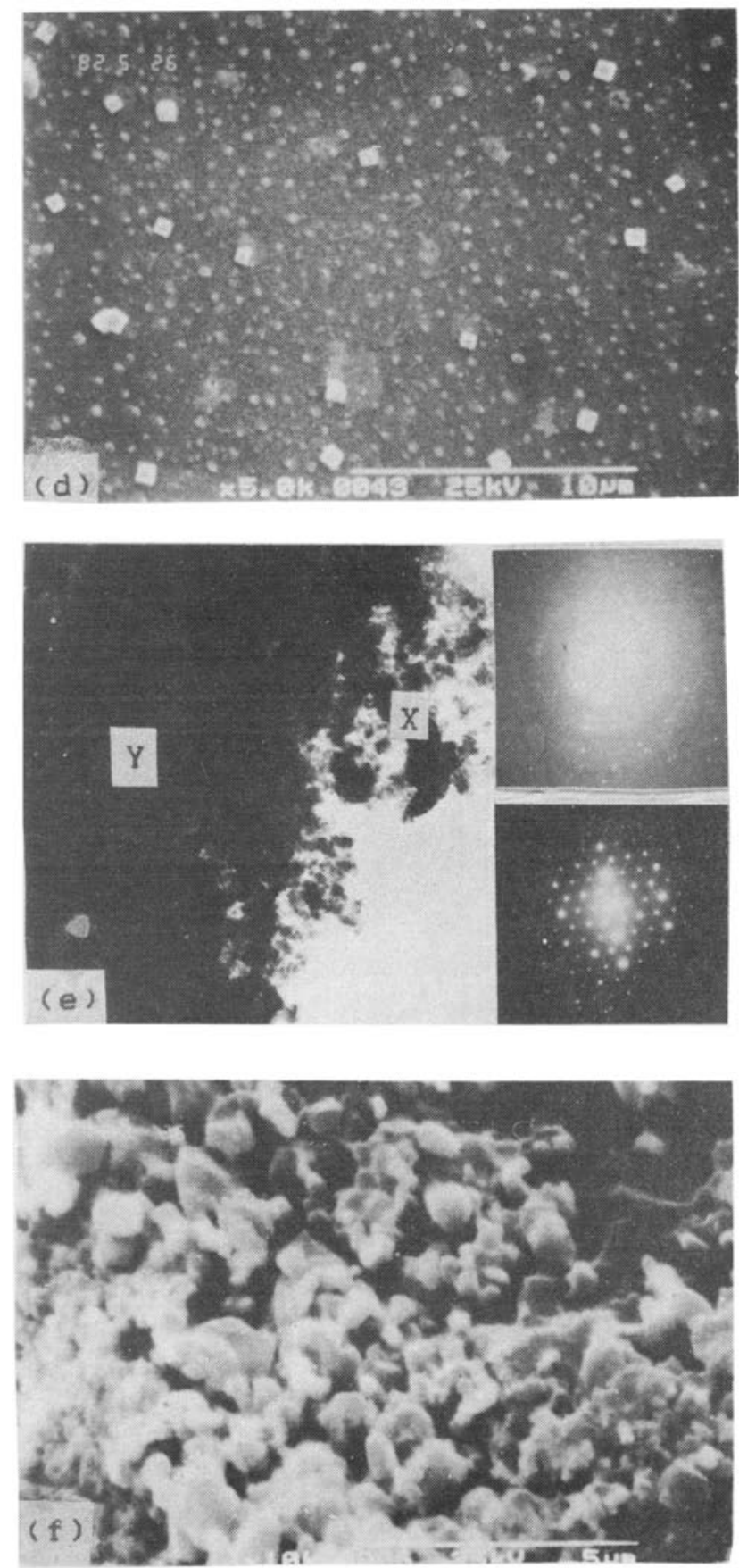

Figure 2. SEM (a, b, c, d and f) and TEM (e) micrographs for some representative diamond films deposited by d.c. magnetron sputtering of vitreous carbon target onto different substrates: a. glass (at $T_{\mathrm{s}} \sim 650 \mathrm{~K}$ ), b. mica (at $T_{\mathrm{s}} \sim 650 \mathrm{~K}$ ), c. molybdenum (at $T_{\mathrm{s}} \sim 1200 \mathrm{~K}$ ), d. mica (at $T_{\mathrm{s}} \sim 1200 \mathrm{~K}$ ), e. $\mathrm{NaCl}$ (at $T_{s} \sim 850 \mathrm{~K}$ with polycrystalline zone, marked $\mathrm{X}$, and single crystalline zone, marked $\mathrm{Y}), T_{\mathrm{s}}$ being the deposition temperature. 

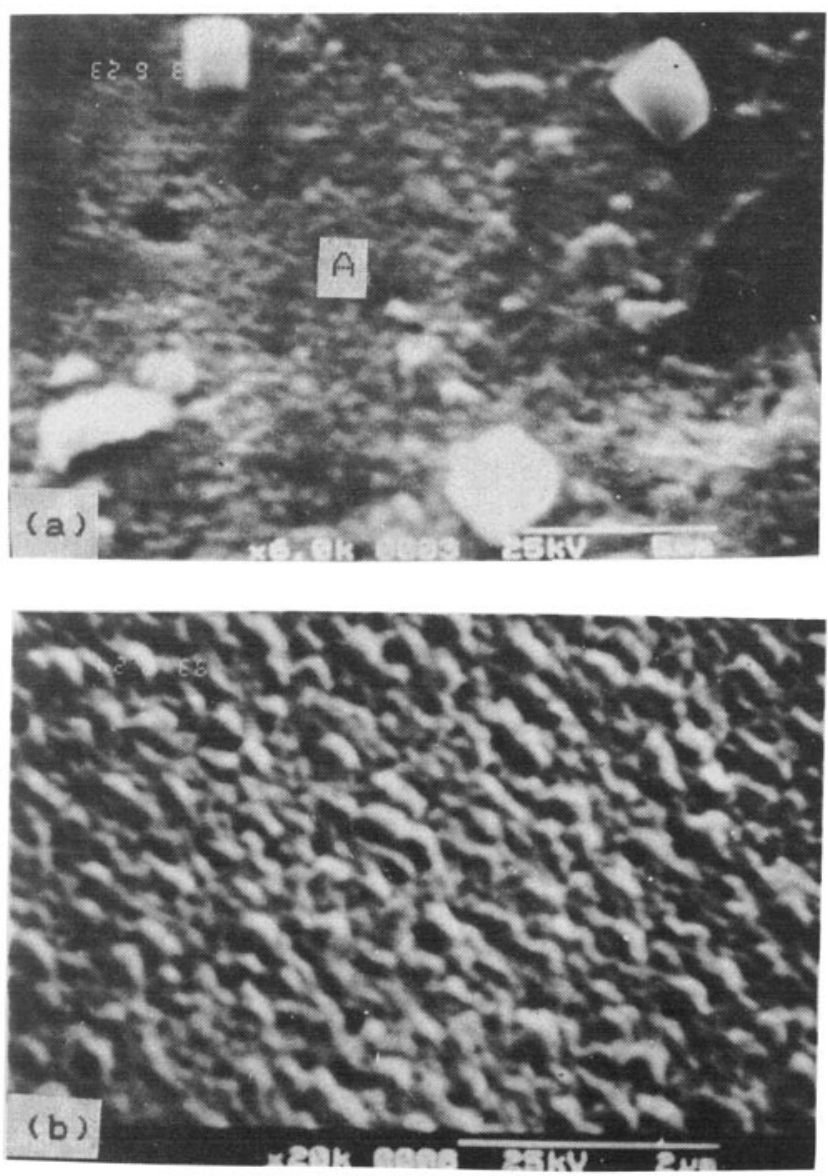

Figure 3. SEM of a representative diamond film deposited by $\mathrm{CVD}$ of $\mathrm{CO}_{2}+\mathrm{H}_{2}(\sim 5$ vol\% $\mathrm{CO}_{2}$ ) on mica substrate. Cubic diamond crystallites are visible in the background (zone A of figure a) of polycrystalline diamond, shown in $\mathbf{b}$.

was recorded in the wave number range $1200-1700 \mathrm{~cm}^{-1}$. Two Raman bands centred at $1332 \mathrm{~cm}^{-1}$ and $1550 \mathrm{~cm}^{-1}$ were observed for most of our films deposited on Si. Formation of diamond was confirmed by a sharp peak at the wave number 1332 $\mathrm{cm}^{-1}$. Figure 5 shows the Raman shift of a film deposited with 4 vol\% of $\mathrm{C}_{2} \mathrm{H}_{2}$ on $\mathrm{Si}$ at $900 \mathrm{~K} . s p^{3}$ bonding in film corresponds to the small peak around 1331.8 $\mathrm{cm}^{-1}$ while the broad band near $1580 \mathrm{~cm}^{-1}$ was attributed to the non-diamond graphite component. The choice of the deposition parameters, mainly the hydrogen content and the substrate temperature during deposition, was varied to control the ratio of $s p^{3}$ to $s p^{2}$ bonding in the film.

\subsection{Optical band gap}

The optical band gap of diamond was measured for films deposited on quartz and mica substrates by recording the transmittance vs wavelength traces in the range 

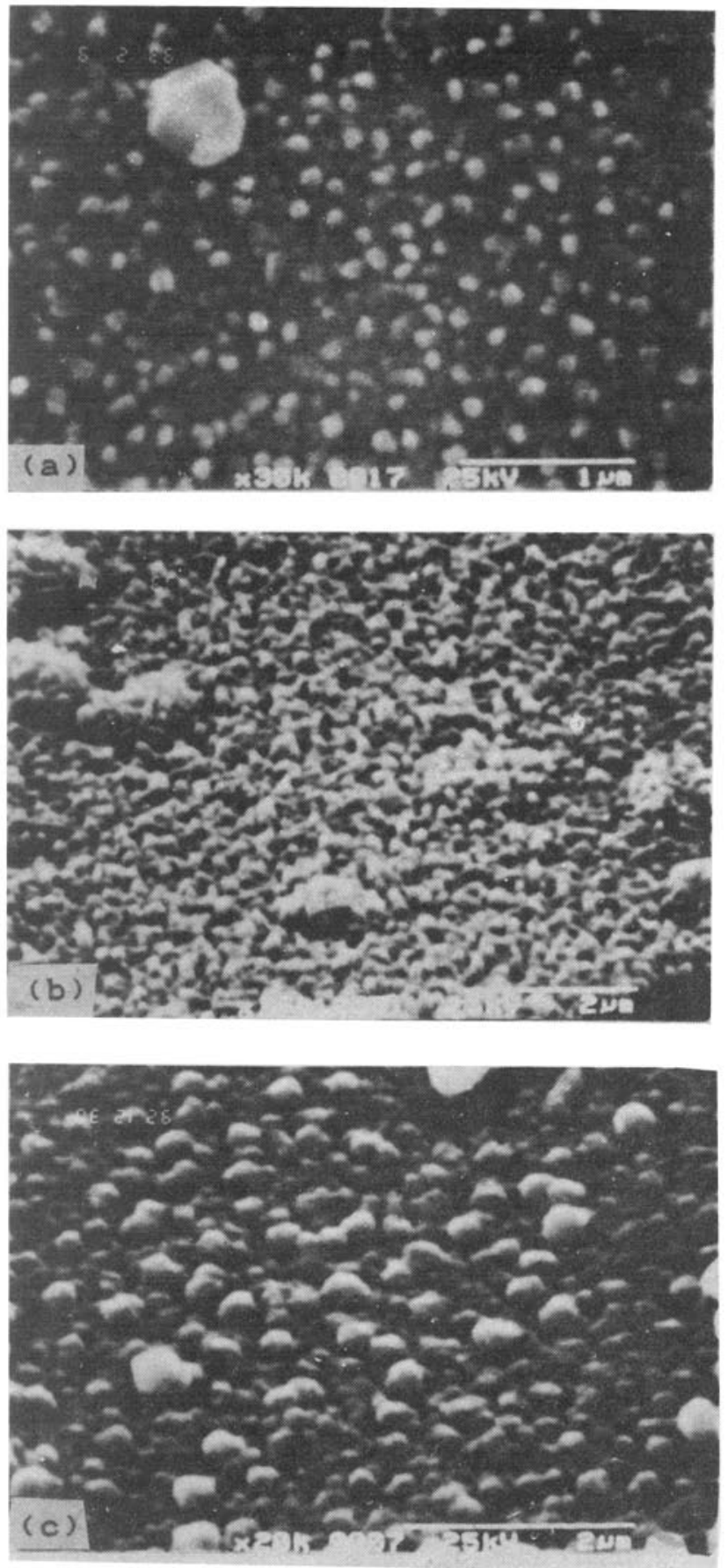

Figure 4. SEM of representative films deposited from CVD of $\mathrm{C}_{2} \mathrm{H}_{2}+\mathrm{H}_{2}(3-5$ vol \%) on different substrates: a. mica, b. quartz and c. Si. 


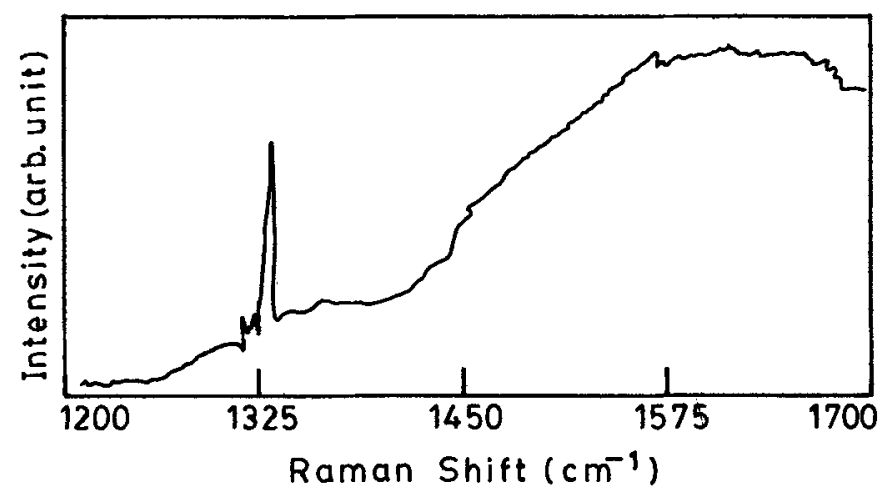

Figure 5. Raman shift of a representative diamond film deposited by CVD of $\mathrm{C}_{2} \mathrm{H}_{2}+\mathrm{H}_{2}$ $\left(\sim 4 \mathrm{vol} \% \mathrm{C}_{2} \mathrm{H}_{2}\right)$ on $\mathrm{Si}$ at $\sim 900 \mathrm{~K}$.

180-2000 nm by a spectrophotometer (Hitachi U-3410). The absorption coefficient $(\alpha)$ in the films varied with incident energy $(h v)$ according to the relation:

$$
\alpha h \vee=B\left(h \vee-E_{\mathrm{g}}\right)^{m},
$$

where $B$ is a proportionality factor, $\alpha$ the absorption coefficient and $m$, a parameter determining the nature of optical transition in the film.

For our CVD films deposited by cracking of acetylene and hydrogen gas mixture, we obtained both $m=2$ and $m=1 / 2$, as shown in figure 6 . This indicates that both indirect and direct transitions may be present in the films which consisted of diamond crystallites embedded in amorphous non-diamond graphite phase. Films deposited with higher $\mathrm{C}_{2} \mathrm{H}_{2}(>5 \mathrm{vol} \%)$ indicated predominant indirect transition with lower band gap (1.5-2.8 eV) while films deposited with lower $\mathrm{C}_{2} \mathrm{H}_{2}(\sim 1-5$ vol\%) indicated predominant direct transition with higher band gap. The highest value of direct band gap obtained in our diamond film was $\sim 4 \mathrm{eV}$. The refractive index of the films was found to vary within 1.8-2.4 with variation of $\lambda$ within $860-1020$ $\mathrm{nm}$, as shown in the inset of figure 6. Films deposited from CVD of $\mathrm{CO}_{2}+\mathrm{H}_{2}$ had direct band gaps within the range $3.8-4.0 \mathrm{eV}$ with a very sharp absorption edge (Chattopadhyay et al 1994b).

Polycrystalline films are generally characterized by the presence of large number of grains joined together by the intercrystalline boundaries (grain boundaries) containing trap states. These trap states could effectively trap free carriers and in turn become charged giving rise to potential barriers at the grain boundary region. These grain boundary regions with inherent space charge layer result in band bending. The Franz-Keldysh effect arising out of the built-in electric field in a semiconducting material may be used to describe the excess absorption below the band gap energy and hence to determine the parameters describing the grain boundary phenomena in these films (Bhattacharyya et al 1993).

Diamond films are generally characterized by the presence of high stress (Nir 1987). Grain boundary defects in a polycrystalline film gives rise to the deformation potential and the consideration of the resulting field at the grain boundary region 


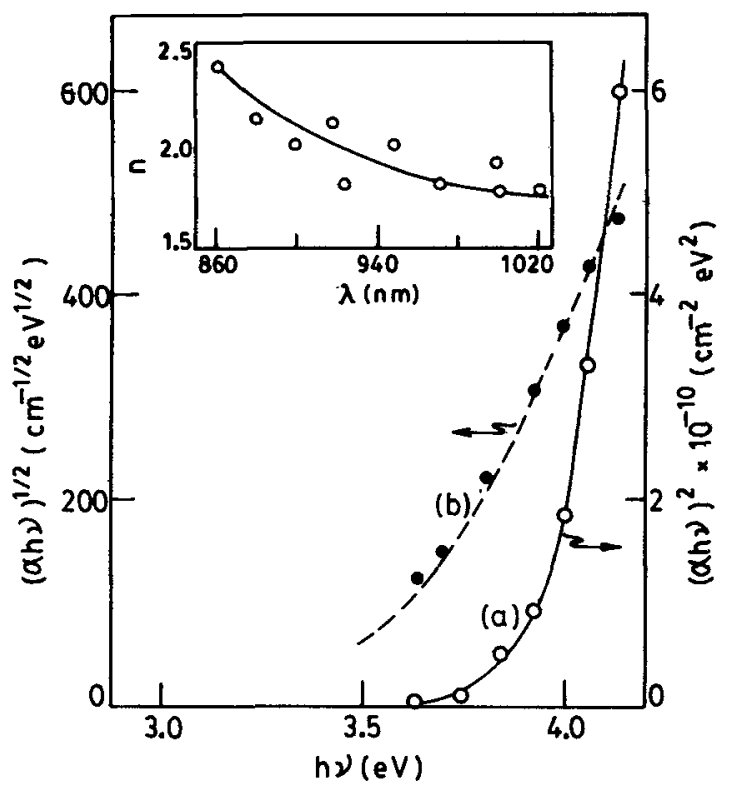

Figure 6. Plot of $(\alpha / v)^{2}$ vs $h v$ (curve a) and $(\alpha / w)^{1 / 2}$ vs $h v$ (curve b) for a representative diamond film deposited by plasma deposition of $\mathrm{C}_{2} \mathrm{H}_{2}+\mathrm{H}_{2}\left(-5\right.$ vol\% $\left.\mathrm{C}_{2} \mathrm{H}_{2}\right)$ on quartz. Inset shows the variation of refractive index $(n)$ with $\lambda$.

and the related induced interaction is very important in describing the grain boundary effects. Thus, besides the grain boundary electric field, the mechanical stress due to lattice distortion at the grain boundary regions which may include permanent lattice disorder and thermal lattice disorder, may also influence the electronic structure and hence the below band-edge optical absorption processes as a whole.

The influence of mechanical stress in the grain boundary region of polycrystalline films may be associated to the electrostatic fluctuations of the band gap $\left(E_{\mathrm{g}}\right)$ as has been indicated earlier by several workers (Szczyrbowski 1979, 1981; Klyava 1985; Gavrilenko 1987; Maity et al 1994a, b). The basic idea of the models considered by the earlier workers is the existence of a finite probability of indirect transitions between the states lying at different and same sites (Maity et al 1994a) in the polycrystalline sample. This will control the specific shape of the absorption tail in the below band gap region. Besides this indirect transition, allowed direct transition may also occur simultaneously in these polycrystalline films. But the latter will predominate only in the photon energy region $\hbar \omega \geq \bar{E}_{\mathrm{z}} \bar{E}_{\mathrm{z}}$ is the average value of the fluctuating $E_{z}$ in the grain and grain boundary regions. Thus, the contribution from the latter on the tailing of the optical absorption is not considered when effect due to grain boundaries are of primary importance.

Thus, one can get the total below band gap absorption coefficient $\alpha\left(=\alpha^{E}+\alpha^{M}\right)$ and hence the normalized absorption coefficient $\alpha / \alpha_{0}$ ( $\alpha_{0}$ being the absorption coefficient at the band gap) due to the combined effects arising out of the electric field $\left(\alpha^{E}\right)$ at the grain boundaries and the mechanical stress $\left(\alpha^{M}\right)$ present in polycrystalline films. The best fit of this simple theoretical model (Maity et al 
1994b) to the experimental plots for films deposited from acetylene and hydrogen gas mixtures $\left(\mathrm{C}_{2} \mathrm{H}_{2}<5\right.$ vol\%) is shown in figure 7 . This will provide unblemished values of the grain boundary potentials $\left(E_{\mathrm{b}}\right)$ and the density of trap states $\left(Q_{\mathrm{v}}\right)$ of polycrystalline semiconductor films. The fitting parameters used for this purpose were $\bar{n}=2.0, a=0.358 \mathrm{~nm}$ and $m^{*}=0.80 m_{0}$, where $\bar{n}, a$ and $m^{*}$ are the average values of refractive index, lattice constant and effective mass of the carriers respectively. The values of the direct band gap $\left(E_{\mathrm{gd}}\right)$, average grain size $(\bar{L})$ and the absorption coefficient $\left(\alpha_{o}\right)$ at the band gap were also used for the above computer fitting (Chattopadhyay et al 1994a).

It may be noticed (figure 7) that the experimental data showed an excellent agreement with the theoretical variation throughout the whole range of measurements provided we consider the contribution of the mechanical stress in the diamond films. We have obtained the values of $E_{\mathrm{b}}$ and $Q_{\mathrm{t}}$ from the values of $K$ (inverse of the Debye length) and $F_{\mathrm{s}}$ (electric field at the grain surface), obtained from the best fit of the data by using the following expressions (Bhattacharyya et al 1993),

$$
Q_{\mathrm{t}}=\varepsilon F_{\mathrm{s}} / q
$$

and

$$
E_{\mathrm{b}}=q F_{\mathrm{s}} / K
$$

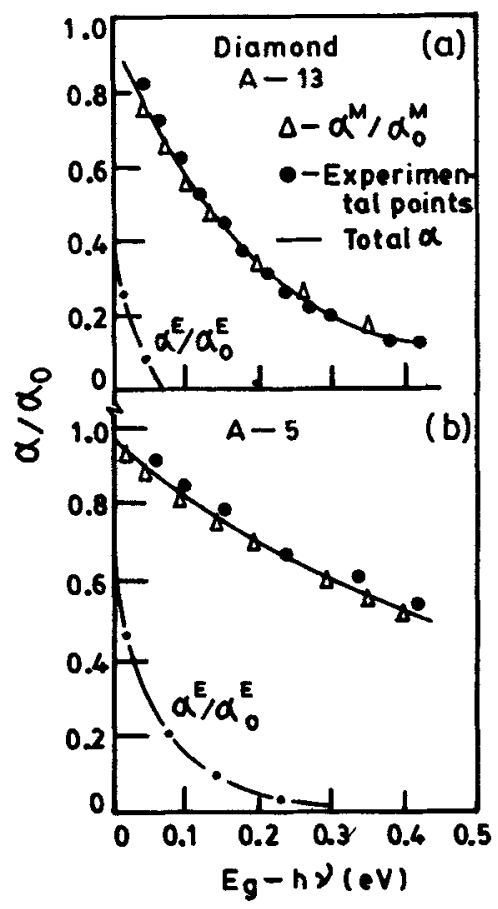

Figure 7. Variation of normalized absorption coefficient $\left(\alpha / \alpha_{0}\right)$ with $\left(E_{z}-h v\right)$ for diamond films deposited by CVD of $\mathrm{C}_{2} \mathrm{H}_{2}+\mathrm{H}_{2}\left(\sim 1-5\right.$ vol $\left.\% \mathrm{C}_{2} \mathrm{H}_{2}\right)$ on (a) quartz and (b) mica substrates. (-) experimental points along with theoretical plots; (-.-.) with $\alpha^{E}$ only; $(\Delta \Delta \Delta)$ with $\alpha^{M}$ only; $(\longrightarrow)$ with both $\alpha^{E}$ and $\alpha^{M}$. 
It was observed that the barrier height $\left(E_{\mathrm{b}}\right)$ in our diamond films, deposited on quartz and mica substrates, varied within $0.36-0.40 \mathrm{eV}$, while the density of trap states $\left(Q_{t}\right)$ varied within $0.4-2.6 \times 10^{13} \mathrm{~cm}^{-2}$.

Now, the strains $(\Delta a / a)$ in the films may be evaluated from the value of a disorder factor $\left(\sigma^{\prime}\right)$ used (Maity et al 1994a, b) for the best fit of the above $\alpha / \alpha_{0}$ vs $E_{g}-h v$ plot (figure 7). The corresponding relations are given in Maity et al (1994a) while the relations related to $\sigma$ and $\Delta a / a$ are given in Maity et al (1994b). The stresses in the films were generated by using the bulk value of the elastic constant (Madelung 1987). A small decrease in stress was observed for films deposited at higher substrate temperatures $\left(T_{\mathrm{s}}\right)$ which attained a plateau region above $\sim 770 \mathrm{~K}$. The trap states varied within $0.4-2.6 \times 10^{13} \mathrm{~cm}^{-2}$ with the decrease in $T_{\mathrm{s}}$ from 770 to $570 \mathrm{~K}$. This would mean that films having higher density of trap states $\left(Q_{8}\right)$ would contain more stress. The values of the stress (2.2-9.3 $\times 10^{9}$ dynes $\mathrm{cm}^{-2}$ ) evaluated as above compared well with those obtained by Wanlu et al (1992), who reported a decrease in the compressive stress with increasing grain size in diamond films deposited from methane and hydrogen by d.c. plasma chemical vapour deposition technique. The analysis presented above showed that the mechanical stress contributes significantly in explaining the absorption band tail of polycrystalline diamond films.

\subsection{FTIR studies}

The formation of well defined diamond crystallites is dependent on the $\mathrm{C} / \mathrm{H}$ ratio in the film along with the rate of deposition. Higher $\mathrm{C} / \mathrm{H}$ ratio and growth rate result in diamond like films. FTIR studies were used to determine the $\mathrm{C} / \mathrm{H}$ ratio in the films produced by cracking $\mathrm{C}_{2} \mathrm{H}_{2}+\mathrm{H}_{2}$ gas mixture. Figure 8 shows FTIR spectrum of a representative film deposited on $\mathrm{Si}$ by using a gas mixture containing 4 vol\% $\mathrm{C}_{2} \mathrm{H}_{2}$ and 96 vol\% $\mathrm{H}_{2}$ within the wavenumber range $400-4000 \mathrm{~cm}^{-1}$. The spectrum shows different vibrational modes. The large intensity of the peak at 1450 $\mathrm{cm}^{-1}$ compared to that at $1375 \mathrm{~cm}^{-1}$ would be indicative of a shift from $s p^{2}$ to $s p^{3}$ bonds.

The tail of the absorption edge in the NIR region can be described by (Dutta et al 1993):

$$
\alpha=\alpha_{\mathrm{us}} \exp \left(v / v_{0}\right)
$$

where $v_{0}$ is the resonant frequency of the corresponding oscillator. The values of $\alpha_{u o}$ and $v_{0}$ were determined from the intercept and the slope of the plot of $\ln (\alpha)$ vs wavenumber $(v)$. The variation of $\alpha$ with $v$ for diamond films was determined for several representative films and was found to be of the form:

$$
\alpha=1569 \exp (v / 7095) \text { for films with } 5 \text { vol\% } \mathrm{C}_{2} \mathrm{H}_{2} \text {, }
$$

and

$$
\alpha=463 \exp (\mathrm{v} / 8536) \text { for films with } 8 \text { vol\% } \mathrm{C}_{2} \mathrm{H}_{2} \text {. }
$$




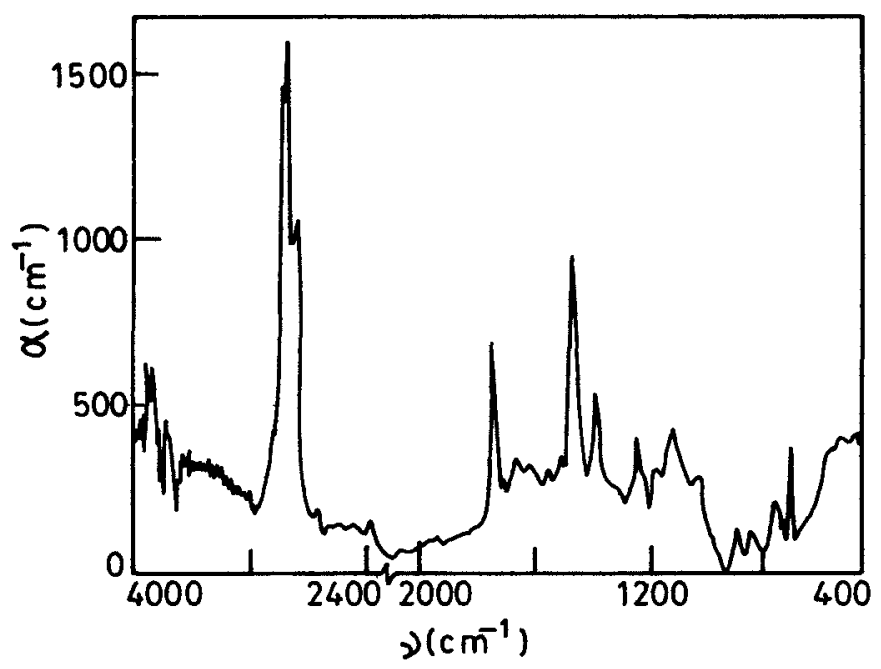

Figure 8. FTIR of a representative diamond film deposited with $\mathrm{C}_{2} \mathrm{H}_{2}+\mathrm{H}_{2}(-4$ vol\% $\mathrm{C}_{2} \mathrm{H}_{2}$ ).

The approximate $\mathrm{H} / \mathrm{C}$ ratio in diamond film is very important since it determines the ratio of $s p^{3} / s p^{2}$ bonding and the shape and size of diamond crystallites. The $\mathrm{H} / \mathrm{C}$ ratio in our diamond film was estimated from the absorption strength of the C-H stretching mode at $2800-3100 \mathrm{~cm}^{-1}$ (Dutta et al 1993). The hydrogen content $\left(\mathrm{C}_{\mathrm{H}}\right)$ is related to the absorbance $\alpha(q)$ by:

$$
\mathrm{C}_{\mathrm{H}}=2.303\left(K_{0} d\right)^{-1} \int_{q_{1}}^{q_{2}} \alpha(q) q^{-1} \mathrm{~d} q,
$$

where $\mathrm{d}$ is the sample thickness in $\mathrm{cm}$ and $q_{1}$ and $q_{2}$ are the wave numbers at both the edges of the absorption peak and $K_{0}$ is a constant in $\mathrm{cm}^{2} / \mathrm{mol}$ which is determined from a standard material containing $\mathbf{C}-\mathrm{H}$ bonds. We have taken $K_{0}=7.8 \times 10^{2}$ so that $C_{H}$ in our films varied within $0.08-0.09$, which compared well with that reported by others (Yasuda and Komiyama 1990; Phillips et al 1992).

\subsection{Electrical conductivity}

The electrical conductivity $(\sigma)$ and Hall mobility $(\mu)$ of the diamond films produced by CVD of $\mathrm{CO}_{2}+\mathrm{H}_{2}$ with different amount of boron doping were measured over a wide range of temperature. The activation energies $\left(E_{\sigma}\right)$ in the films decreased with increasing boron concentration. The films showed a predominant $p$-type conductivity as determined from Hall effect measurements. The variation of $\sigma$ and $\mu$ with temperature exhibited two distinct slopes obeying the relations:

$$
\begin{gathered}
\sigma=\sigma_{0} \exp \left(-E_{\sigma} / k T\right), \\
\mu=\mu_{0} \exp \left(-E_{\mu} / k T\right) .
\end{gathered}
$$


The carrier concentration $(p)$ also indicated similar variation so that

$$
p=p_{0} \exp \left(-E_{\mathrm{p}} / k T\right)
$$

The measurement within the temperature range $90-500 \mathrm{~K}$ indicated

$$
E_{\sigma}=E_{\mu}+E_{p} \text {, }
$$

as suggested by Petritz (1956). This shows that grain boundary scattering will effectively control the carrier transport phenomenon in these films. The presence of interface states along with thermionic emission across the grain boundaries will directly affect the charge transport mechanism in polycrystalline films and the Petriz model modified by Seto (1975) and Baccarani et al (1978) was considered so that the temperature dependence of mobility $(\mu)$ will determine the barrier height $\left(E_{b}\right)$ following the relation:

$$
\mu=L e\left[1 / 2 \pi m^{*} k T\right]^{1 / 2} \exp \left(-E_{b} / k T\right)
$$

where $L$ is the grain radius in the film and $m^{*}$ the effective mass of the carriers. Plot of $\ln \left(\mu T^{1 / 2}\right)$ vs $(1 / T)$ was a straight line and the slope of it gives $E_{\mathrm{b}}$. The density of trapping states $\left(Q_{\mathrm{t}}\right)$ at the grain boundaries of the polycrystalline diamond films is given by (Seto 1975):

$$
E_{\mathrm{b}}=e^{2} Q_{\mathrm{t}}^{2} / 8 \varepsilon p
$$

where $\varepsilon$ is the dielectric constant. $E_{\mathrm{b}}$ was found to decrease with increase in carrier concentration $(p)$ indicating partial depletion of the grains in these polycrystalline boron doped diamond films in which $L p \gg Q_{1}$ (Mitra et al 1994). It was observed that with the increase in doping density the carrier concentration (p) varied within $1.0 \times 10^{17}$ to $5.0 \times 10^{18} \mathrm{~cm}^{-3}$ and the corresponding variation of $Q_{\mathrm{t}}$ was within $6.0 \times 10^{11}$ to $4.0 \times 10^{12} \mathrm{~cm}^{-2}$.

\section{Conclusion}

Diamond films, deposited on different substrates (e.g. Mo, glass, mica, $\mathrm{Si}$ and quartz) by d.c. magnetron sputtering and $\mathrm{CVD}$ of $\mathrm{C}_{2} \mathrm{H}_{2}+\mathrm{H}_{2}$ or $\mathrm{CO}_{2}+\mathrm{H}_{2}$ with substrate temperature within the range $500-1200 \mathrm{~K}$ indicated that a high substrate temperature $(\sim 1000-1200 \mathrm{~K})$ always favoured the nucleation of diamond crystallites. The optical band gap of diamond films were determined and showed a wide variation within $1.8-4.0 \mathrm{eV}$ depending on the deposition technique and the deposition condition. It was observed that the films deposited from CVD of $\mathrm{C}_{2} \mathrm{H}_{2}+\mathrm{H}_{2}$ (with $\mathrm{C}_{2} \mathrm{H}_{2}$ in the range 1-5 vol\%) produced diamond films with higher band gap $\left(>3.5 \mathrm{eV}\right.$ ), while films deposited with $\mathrm{C}_{2} \mathrm{H}_{2}$ above 5 vol\% were diamond like carbon (DLC) films with lower band gap (1.5-2.8 eV). A sharp band gap at $\sim 4.0$ eV was observed for films deposited by CVD of $\mathrm{CO}_{2}+\mathrm{H}_{2}\left(3-5\right.$ vol\% of $\left.\mathrm{CO}_{2}\right)$.

TEM observations indicated the films to be polycrystalline. The effect of grain boundaries in the polycrystalline diamond films were studied from the below band 
gap absorption measurements. A theoretical fit of the experimental data indicated grain boundary barrier height of $\sim 0.36-0.40 \mathrm{eV}$ and the density of the trap states at the intercrystalline boundary region varied within $0.40-2.5 \times 10^{13} \mathrm{~cm}^{-2}$. The effect of mechanical stress in the film (deposited by CVD of $\mathrm{C}_{2} \mathrm{H}_{2}+\mathrm{H}_{2}$ ) was also determined from the above optical measurements which indicated that the stresses in the diamond films varied within $2.2-9.3 \times 10^{9}$ dyne $\mathrm{cm}^{-2}$. The quality of the films was studied by Raman effect which indicated a sharp peak at $-1332 \mathrm{~cm}^{-1}$. These studies were correlated with FTIR observations.

\section{References}

Baccarani G, Ricco B and Spadini G $1978 \mathrm{~J}$. Appl. Phys. 495565

Badzian A R, Badzian T and Pilione L 1989 3rd Int. conf. on surface modification technologies, Neuchatel

Bhattacharyya D, Chaudhuri S and Pal A K 1993 Vacuum 44797

Bögli U, Bächi A and Blatter A 1994 Rev. Sci. Instrum. 65943

Brown A S 1987 Aerospace Am. 2512

Celii F G, White D Jr and Purdes A J 1992 Thin Solid Films 212140

Chattopadhyay K K, Dutta J, Chaudhuri S and Pal A K 1993 Mater. Lett. 16145

Chattopadhyay K K, Dutta J, Chaudhuri S and Pal A K 1994a Diamond and related materials (in press)

Chattopadhyay K K, Mitra P, Chaudhuri S and Pal A K 1994b Mater. Lett. 18313

Chen K H, Chuang M C, Penney C M and Banholzer W F 1992 J. Appl. Phys. 711485

Collins A T 1989 Semicond. Sci. Technol. 4605

Collins A T 1990a in Diamond silicon carbide and related wide band gap semiconductors, Mat. Res. Soc. Symp. Proc. (eds.) J T Glass, R Messier and N Fujimori (Pittsburgh, USA: Mater. Res. Soc.) 162 p. 3

Collins A T, Kamo $M$ and Sate $Y 1990 \mathrm{~b}$ in Diamond silicon carbide and related wide band gap semiconductors, (eds.) J T Glass, $R$ Messier and N Fujimori (Pittsburgh, USA: Mater. Res. Soc.) 162 p. 225

Collins A T 1992 Mater. Sci. Eng. B11 257

DeNatale J F, Hood P J, Flintoff J F and Harber A B 1992 J. Appl. Phys. 711388

Dutta D, Chattopadhyay K K, Dutta J, Chaudhuri S and Pal A K 1993 Mater. Lett. 18114

Ford I I 1994 Thin Solid Films 245122

Fujimori N, Nakahata H and Imai T 1990 Jap. J. Appl. Phys. 29824

Gavrilenko V I 1987 Phys. Status Solidi B139 457

Geis M W, Smythe D L, Zayhowski J J, Rothschild M, Ehrlich D J, Smith D K and Ditmer G A 1988 in Diamond and diamond like materials synthesis, (Pittsburgh, USA: Mat. Res. Soc.) EA-15 p. 115

Gildenblat G Sh, Grot S A, Hatfield C W, Badzian A R and Badzian T 1990 IEEE Electron Device Lett. 11371

Glesener J W 1993 Appl. Phys. Lett. 63767

Glesener J W 1994 Appl. Phys. Lett. 64217

Glesener J W, Morrish A A and Snail K A 1991 J. Appl. Phys. 705144

Glesener J W, Morrish A A and Snail K A 1992 Appl. Phys. Lett. 61429

Glumac N G and Goodwin D G 1992 Appl. Phys. Lett. 602695

Grot S A, Hatfield C W, Gildenblat G Sh, Badzian A R and Badzian T 1991 in New diamond science and technology, Mat. Res. Soc. Proc. (eds.) R Messier, J T Glass, J E Butler and R Roy (Pittsburgh, USA) p. 949

Guo F S and Yu S C 1992 Thin Solid Films 212133

Holiday P, Dehbi-Alaoui A and Matthews A 1992 Mater. Sci. Forum 102-104 643

lhara M, Maeno M, Miyamoto K and Komiyama H 1991 Appl. Phys. Lett. 591473

Koizumi S, Murakami T and Inuzuka T 1990 Appl. Phys. Lett. 57563

Klyava Y G 1985 Soviet Phys. Solid State 27816

Liou Y, Inspektor A, Weimer R and Messier R M 1989 Appl. Phys. Lett. 55631

Madelung $O$ (ed.) 1987 Landolt-Börnstein numerical data and functional relationships in science and 
technology (Berlin: Springer) 22 p. 9

Matthews A and Eskildsem S S 1994 Diamond \& Related Mater. 3902

Mitra P, Chattopadhyay K K, Chaudhuri S and Pal A K 1994 Mater. Lett. 2195

Maity A B, Bhattacharyya D, Chaudhuri S and Pal A K 1994a Vacuum (in press)

Maity A B, Chaudhuri S and Pal A K $1994 b$ Phys. Status. Solidi. B183 185

Nir D 1987 Thin Solid Films 14627

Ong T P and Chang R P H 1989 Appl. Phys. Lett. 552063

Petritz R L 1956 Phys. Rev. 1041508

Phillips R, Wei $J$ and Tzeng Y 1992 Thin Solid Films 21230

Saito Y, Sato K, Gomi K and Miyadera H 1990 J. Mater. Sc. 251246

Sawabe $A$ and Inuzuka $T 1986$ Thin Solid Films 13789

Seto J Y W 1975 J. Appl. Phys. 465247

Simpson M 1988 New Sci. 11750

Szczyrbowski J J 1979 Phys. Status Solidi 196769

Szczyrbowski J J 1981 Phys. Status Solidi B105 515

Tachibana T, Glass J T and Thompson D G 1993 Diamond \& Related Mater. 237

Vasudev A, More K L, Ailey-Trent K S and Davis R F 1993 J. Mater. Res. 81101

Vermeulen L A and Harris A J 1997 Diamond Res. Suppl. Ind. Diam. Rev. 3725

Wanlu W, Kejun L, Jinying G and Amin L 1992 Thin Solid Films 215174

Wu R L C, Rai A K, Garseadden A, Kee P, Desai H D and Miyoshi K 1992 J, Appl. Phys. 72110

Yasuda T and Komiyama H 1990 Jap. J. Appl. Phys. 29361

Yoder M N 1987 Nav. Res. Rev, 3927 